\title{
Poultry Egg Incubation: Integrating and Optimizing Production Efficiency
}

http://dx.doi.org/10.1590/1806-9061-2016-0292

Review

mAuthor(s)

\author{
Boleli IC' \\ Morita VS' \\ Matos Jr JB' \\ Thimotheo $\mathrm{M}^{\prime}$ \\ Almeida VR'
}

Department of Animal Morphology and Physiology, São Paulo State University, Access road Professor Paulo Donato Castellane, s/n, 14884-900, Jaboticabal, Sao Paulo, Brazil

\section{-Mail Address}

Corresponding author e-mail address Isabel Cristina Boleli

Departamento de Morfologia e Fisiologia Animal, Faculdade de Ciências Agrárias e Veterinárias, Universidade Estadual Paulista-UNESP - Jaboticabal, 14884-900, São Paulo, Brasil.

Email: icboleli@fcav.unesp.br

\section{Eeywords}

Gas exchange, heat transfer, incubation conditions, incubation management, physics of incubation.

\section{ABSTRACT}

Due to its central position in the production chain, in-ovo development is influenced by pre-incubation factors that affect the quality of embryonated eggs and incubation conditions themselves, and both may influence egg hatchability and chick quality, as well as bird survival, growth performance, and phenotype in the field. The evolution of the incubation process over the years is characterized by significant scientific and technological development. Presently, the main current focuses of research are the manipulation of thermal incubation conditions, eggshell temperature, and the integrated effects of factors that influence incubation. In this context, one of the questions that needs to be asked is how effective are the current physical conditions of incubation to promote greater hatchability and better quality chicks, and higher survival and better performance in the field under adverse conditions or not. What are the new and future prospects for incubation? The purpose of this paper was to review the role of the physical agents of incubation, such as temperature, relative humidity, $\mathrm{O}_{2}$ and $\mathrm{CO}_{2}$ concentration, and egg turning and position from an integrated perspective, considering egg incubation as the transitional link between egg and poultry production.

\section{INTRODUCTION}

Over the past 50 years, global annual meat production has almost quadrupled from 78 million tons in 1963 to 308 million tons in 2015, achieving an impressive growth from about 205 million tons to 319 million tons between 1995 and 2015. During these last two decades, the production of poultry meat increased almost $108 \%$ increase (from 54 to 112 million tons), corresponding to a 36\% growth of its share in total meat production (Avisite, 2015; SNA News, 2015). Meat production is estimated to double by 2020-2022 due to the growth of the global population and of meat consumption per capita. According to this trend, global consumption of poultry meat is estimated in 128 million tons by 2022 (OACD / FAO Agricultural Outlook, 2015).

In order to meet this high demand for poultry meat, hatcheries need to maximize chick production, and this entails not only the incubation of more fertile eggs. Today, hatcheries need to achieve high production efficiency in a sustainable manner, which, in our view, includes maximizing the hatchability of healthy chicks with high survival rates and the maximum expression of their genetic growth potential under any conditions in the field.

Scientific knowledge on incubation acquired over the years shows that the physical factors to which the eggs are subjected before and during incubation determine the production efficiency of hatcheries and poultry farms. Nevertheless, little is known about the effective 
participation of the integrated effects of physical factors during ontogenetic development on the phenotype of poultry during the different stages of production.

\section{INCUBATION REVOLUTION}

In the last few years, artificial egg incubation systems have experienced a technological, economic, and social revolution. Remarkable technological and scientific developments allowed the transition from manual incubation to large incubation machines and hatcheries, which incubate a much greater number of eggs using less labor, increasing chick production throughout the year. On the other hand, this incubation revolution generated costs related to the construction of more sophisticated facilities, as well as operational costs, such as energy and water expenses to maintain adequate incubation conditions. It also influenced social relations, creating two classes: producers and consumers.

The principles of artificial egg incubation were established centuries ago. At that time, heat, moisture and air renewal of the incubation environment, well as the egg turning, were already taken into consideration. Based in historical records, Paniago (2005) and van den Sluis (2011) mention that, in ancient Egypt, eggs were incubated in mud-brick buildings (an "incubation house") divided in incubation chambers similar to ovens separated by a central hallway and accessible through manholes. In the upper part of the egg chambers, there were shelves for burning, straw, dung, or charcoal to heat the eggs below. Vents in the roof allowed the smoke from the fires to escape and provided some light. In this primitive incubation system, the temperature within the incubation chambers was managed by controlling fire intensity and opening the manholes, vents, and the hallway. Humidity was controlled by placing moistened jute on eggs, which were manually turned twice per day. Mechanical incubating was not invented until the year of 1749 by Reamur in Paris, France, and the first commercial incubator was manufactured by Hearson in 1881.

An incubator should to be able to regulate factors, such as temperature and humidity, and to allow air renewal and egg turning, providing the perfect environmental conditions for embryonic development, aiming at achieving high hatchability of healthy chicks, which is directly correlated with the survival and performance of individual chicks in the field. Currently, incubators capable of incubating different numbers of eggs of different species of birds are commercially available, with more or less sophisticated of temperature, humidity, ventilation, and egg turning control systems. Modern state-of-the-art commercial hatcheries are provided with automatic systems controlling all the physical factors of incubation: egg turning; environmental temperature set according to eggshell temperature determined by thermosensors; air relative humidity and egg water loss determined by egg tray weight using weight sensors; and air quality $\left(\mathrm{O}_{2}\right.$ and $\mathrm{CO}_{2}$ levels). However, as already pointed out by Paniago (2005), despite the technological advances of the modern incubation machines, the success of incubation still depends on the quality of labor both inside and outside the hatcheries, which requires training.

\section{PHYSICS OF EGG INCUBATION: AN INTEGRATED PROCESS}

From a macroscopic point of view, although the external and egg internal environments seem to be completely isolated, the eggshell participates in and allows exchanges between those two environments, as determined by the interaction among temperature, relative humidity, ventilation (air quality) and egg turning during incubation, which are essential for the success of embryonic and fetal development. The physical exchanges between the egg and the external environment (egg and air of the incubator) include heat transfer and the exchange of $\mathrm{O}_{2} \mathrm{CO}_{2}$ and water. Egg characteristics (size, composition, and shape, and eggshell thickness, porosity, and heat and water vapor conductance), embryo metabolism rate and physical incubation conditions, as well as preincubation conditions, may cause deviations from the optimal values of these physical agents (Figure 1). Such deviations may can interfere with, or even hinder, in-ovo development, resulting in negative effects on hatchability and on the quality of the hatchlings and their subsequent performance, phenotype, and survival. In contrast, optimal physical incubation conditions benefit egg hatchability and chick quality, with possible survival and performance benefits.

\section{Egg heat transfer}

Heat transfer occurs when there is a temperature difference between two regions or media, and always on the thermal gradient. Eggs present four mechanisms for heat transfer: conduction, radiation, convection, and evaporation (Meijerhof \& van Beek, 1993; French, 1997). However, eggs gain or lose heat only 


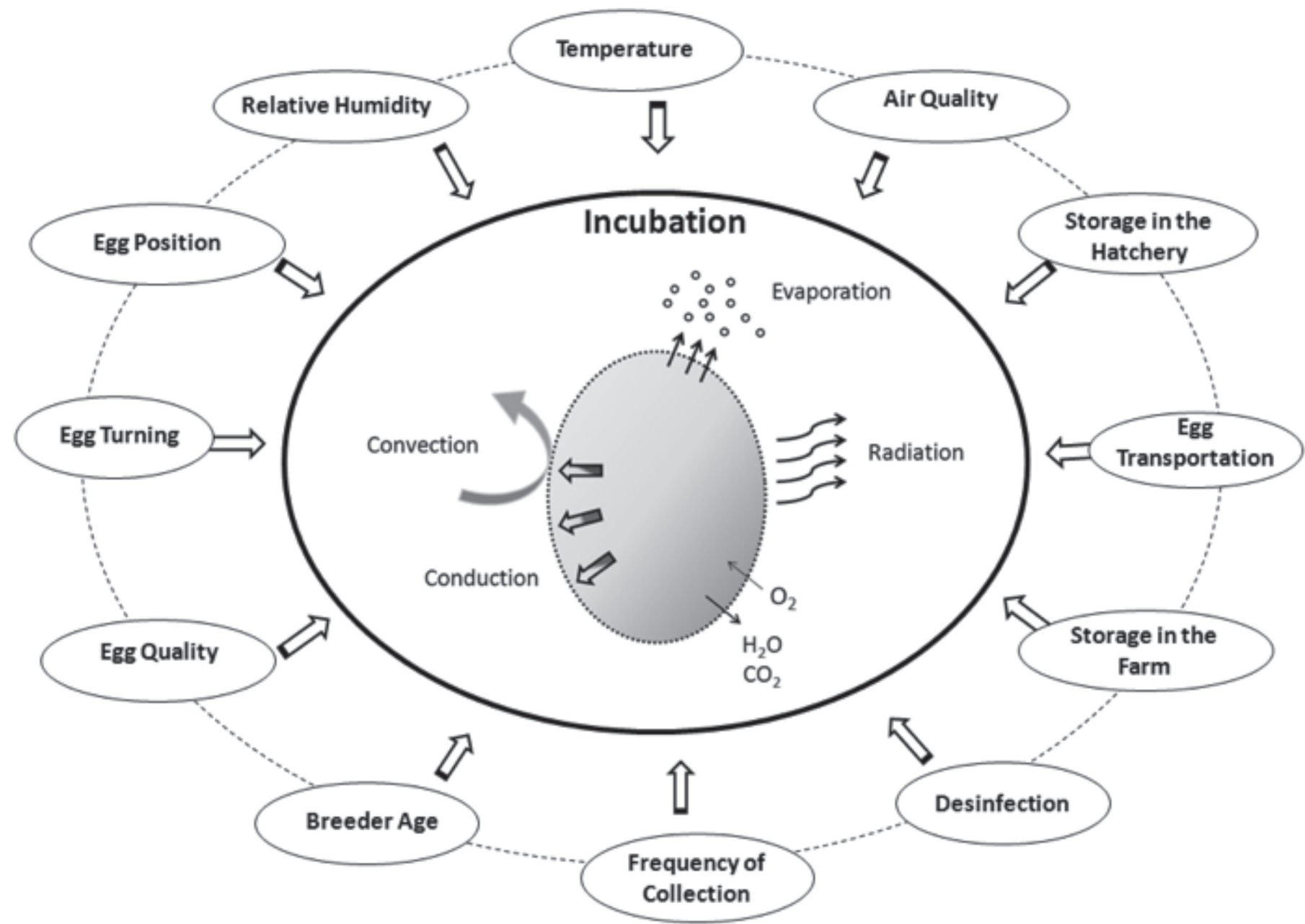

Figure 1 - Physical exchanges of the eggs with the environment during incubation (heat transfer, water loss and gases exchanges) depend of the egg characteristics (size, composition, form, and eggshell thickness, porosity and heat and water vapor conductance), embryo metabolism rate and physical incubation conditions, but also of the pre-incubation conditions.

when there is a temperature difference between the environment and the eggshell, and this is influenced by several factors associated with egg quality (breeder age; egg size, composition, and shape; and eggshell characteristics), water loss, and incubation conditions.

Conduction: Heat transfer by conduction occurs between regions or media that are in contact with each other, from the warmer to the colder regions. Heat transfer rate by conduction depends on the temperature difference and the thermal conductivity of the regions involved. Therefore, in the egg, heat is transferred by conduction from the embryo to the eggshell, provided their temperatures are different, as well as to the air layer in direct contact with the eggshell. Eggs gain or lose heat when air temperature is warmer or colder than the eggshell, respectively. However, heat transfer by conduction inside the eggs is faster than that from the eggs to the air, because the water present in the eggs has higher thermal conductivity compared with air. Therefore, conduction accounts only for a small portion of heat transfer from the egg to the environment. This also means that the heat transfer by conduction between the embryo and the egg surface depends of the egg water content and may be influenced by egg water loss. Other factors influence heat transfer by conduction, such as egg size, eggshell thickness, and embryo metabolic heat production rate, which is determined by egg size and thermal incubation conditions.

Convection: Convective heat transfer refers to heat transfer by air currents, and occurs when a body loses heat by conduction. Therefore, when eggs lose heat by conduction to the surrounding air, the air near the eggshell is warmed and rises, moving cooler air moves near the eggshell in replacement of the warm air, generating convection currents, which help to remove heat from the egg. It should be emphasized that convection currents are essential for the egg to continue to lose heat by conduction, because conductive heat loss does not take place when the air temperature near the 
eggshell is similar to that of the eggshell. In this context, air movements across the eggshell surface in the setter and the egg turning program (tilt angle, velocity, and frequency) should be taken into consideration, because they influence conductive-convective heat dissipation from the eggshell. More or less intense movements of the air or of the eggs in the setter increase or decrease, respectively, egg heat loss by conduction and convection and may influence embryo and/or fetal development and, consequently, incubation production efficiency. The rate of heat transfer by conduction and convection from the eggs to the environment are required for optimal in-ovo development. However, this rate changes during incubation according to the physical incubation conditions, determined by temperature, relative humidity, air movement, and egg turning, as well as to eggshell characteristics, such as total surface area, thickness, and conductivity.

Radiation: Radiant heat transfer occurs from the surface of a warm body by emission of heat waves that propagate through air. On the other hand, when radiant energy is absorbed by a body, it is transformed into heat. According to this thermodynamic principle, egg heat loss or gain by radiation depends on the temperature difference between egg surface and the surfaces in the incubation environment. Therefore, radiant heat transfer allows heating the eggs. The sources of radiant heat used throughout the history of artificial incubation, were the sun, burning of coal, manure, or gases, electricity, etc. However, the exposure of eggs to environmental temperatures higher than the eggshell temperature (very high incubation temperature) may increase conductive and radiant heat gain by the eggs, which in turn experience hyperthermia and may compromise embryonic and fetal development due to the lack of compensatory heat loss. According to these principles, radiant heat loss occurs when the eggs are exposed to temperatures lower than the eggshell temperature. The exposure of eggs to low environmental temperature causes hypothermia, reducing or precluding embryonic and fetal development, and may lead to both embryonic or fetal death.

Evaporation: According to laws of thermodynamics, evaporative heat loss occurs when water is changed from liquid into gas, because this reaction requires heat. In addition, the flow of water vapor occurs from high vapor pressure or high humidity to low vapor pressure or low humidity, respectively. For this reason, eggs lose heat by evaporation by the diffusion of water molecules through the eggshell pores as a result of the higher water vapor pressure inside the eggs relative to the outside. This means that evaporative heat loss is determined by eggshell conductance, which depends on eggshell pore number, size, and shape; and on the incubation physical conditions established by temperature, air relative humidity, air movement, and egg turning. Evaporative heat loss from the egg is of $2,26 \mathrm{KJ}$ per gram of water loss, and causes the cooling of the eggshell (Meijerhof, 2013), which is important for the establishment of heat loss by conduction.

\section{Egg Water transfer}

Water diffusion is a physical process that, according to Fick's laws, is the movement of water molecules down a concentration gradient. The diffusion flow is given by concentration gradient and by temperature: the higher the gradient and the temperature, the faster is the water diffusion. Eggs lose water by diffusion through the eggshell as a result of the water pressure differences between the inside and the outside of the egg, as determined by the temperature and relative humidity of both sides. Egg water loss depends of eggshell porosity (Deeming, 2002), given by its pore number, diameter, length, and shape. Therefore, it is higher in eggs laid older breeders or larger eggs from a same breeder age incubated at high temperatures and/or low relative humidity levels (Morita et al., 2009, 2010; Sgavioli et al., 2015). Although the velocity of the air on the egg surface has no direct effect on water loss (Meijerhof \& van Beek, 1993), as previously mentioned in this review, it allows continuous conductive-convective heat dissipation, and therefore, indirectly influences egg water loss.

Egg water content is a finite quantity of water deposited in the yolk and in the albumen during the ovarian folliculogenesis and egg production in the lateral oviduct of the birds. Egg water content corresponds to just over $70 \%$ of its initial weight (74.3\% in chickens, $71.8 \%$ in guinea fowls, $71.9 \%$ in turkeys, $70.3 \%$ in geese and ducks, and $73.4 \%$ in quails (Romanoff \& Romanoff, 1949; Panda \& Singh, 1990). During incubation, egg water content is absorbed by the embryo and fetus from embryonic annexes (amniotic cavity, allantois, yolk sac), (Davis, 1988; Ar, 2004), whereas a small portion is lost to the external environment (Drent, 1970; Ar \& Rahn, 1980). In addition, metabolic water is also produced inside the eggs by embryo lipid metabolism, and particularly by fetal lipid metabolism during the last week of incubation (Boerjan, 2006), accounting for 8 to $13 \%$ of the fetal water content (Ar, 2004). 
As previously mentioned in this paper, water loss during incubation is associated with egg heat loss by evaporation and conduction. However, water loss is important not only for egg heat loss, but also for the formation of the air chamber. The volume of the water lost is replaced by an equivalent volume of gas, determining the size of the air chamber (Visschedijk, 1968). When the egg air chamber is small $(<1.8$ inches), the chicks are not able to perform internal pipping; they pip below the inner membrane and die by drowning in the fluid still present in the amniotic and allantoic cavities. On the other hand, large air chambers (> 3.16 inches), indicate that the fluid has dried, and the chicks are born weak and adhered to the eggshell. Egg water loss is also important by gas exchange through the eggshell, as they occur through the same pores.

\section{Egg $\mathrm{O}_{2}$ and $\mathrm{CO}_{2}$ exchanges}

In-ovo development requires that all embryonic, fetal, and embryonic annex cells are supplied with the energy required for their survival, proliferation, migration, and differentiation. Energy utilization demands aerobic respiration, efficient oxygen supply, and carbon dioxide elimination. The demand for gas exchange increases during incubation as a result of the increasing metabolic rate of the embryo, according to its different developmental stages, i.e., embryo morphogenesis, fetal growth, and hatching. In order to ensure efficient gas exchange during inovo development, different surfaces are used. During the first three days of incubation, gas exchanges are carried out directly by the embryonic cells. As the embryo develops, the amniotic cavity is formed, which makes the direct gas diffusion from the embryonic cells inefficient, demanding the establishment of gas transport systems. From the third day of incubation, with the emergence of the embryonic circulatory system and yolk vascularization, gas exchange is exchanged through the vitelline vessels. Yolk vascularization continues as the embryo develops, increasing the surface area of gas exchange. However, fetal development requires greater $\mathrm{O}_{2}$ supply than that provided by vitelline gas exchange. Furthermore, vitelline circulation is disappears as the yolk sac is incorporated in the fetal abdominal cavity, and its contents start to be absorbed exclusively by the intestinal route. Therefore, by days 10-12 of incubation, gases start to be exchanged by the allantoic vessels, which supply the high oxygen requirements for increased fetal metabolism thereafter (Hamburger \& Hamilton, 1951; Tazawa, 1980; Deeming, 2002;
Mortola, 2009). After internal pipping, gases gradually begin to be exchanged via the pulmonary respiratory system (Decuypere \& Bruggeman, 2006; Mortola, 2009), and $\mathrm{O}_{2}$ deficit and $\mathrm{CO}_{2}$ saturation inside the egg air chamber are the main factors that induce external pipping and hatching per se (Mortola, 2009). In addition to changes in the gas exchange surfaces, hematological adjustments also occur, increasing gas exchange capacity during incubation: red blood cell counts (RBC), hematocrit $(\mathrm{Ht})$ values, hemoglobin $(\mathrm{Hb})$ levels increase, while mean corpuscular volume decreases (Morita et al., 2009; Tazawa et al., 2011, 2012).

Nevertheless, all those morphological and physiological adaptations do not ensure the efficiency of gas exchange. The embryonic and fetal development of the birds inside the eggs requires gas exchange primarily between the egg and the incubation environment. Therefore, gas exchange through the eggshell requires gas concentration differences between internal and external egg environments. If the $\mathrm{O}_{2}$ concentration outside the eggs is higher than that present inside the egg, oxygen is diffused into the egg. If the $\mathrm{CO}_{2}$ concentration is higher inside than outside the eggs, $\mathrm{CO}_{2}$ diffuses in the opposite direction, i.e., out of the egg. Therefore, the concentration of these gases in the setter are essential for embryonic and fetal $\mathrm{O}_{2}$ supply and $\mathrm{CO}_{2}$ elimination.

\section{INCUBATION PHYSICAL CONDITIONS}

\section{Air relative humidity}

As mentioned above, egg water loss during incubation is essential for adequate in-ovo development; however, water losses outside a normal range may result in chick abnormalities or death in ovo. Low air relative humidity during incubation may cause excessive egg water loss, resulting in embryo dehydration and death (Reinhart \& Hurnik, 1984) or the hatching of small and dehydrated chicks (van der Pol et al., 2013), due to fluid deficit in the amniotic and allantoic cavities, which impairs embryonic development and hatching. However, hatchlings with low body weight, as a result of skin and muscle dehydration, may present compensatory growth between 7 and 10 post-hatch, and normal development thereafter (Davis et al., 1988). On the other hand, if the air relative humidity is too high, the incubation period is shortened, and the chicks are wet at hatch and residual albumen may be present (Taylor, 1999; Decuypere et al., 2002; Tona et al., 2003). 
Air relative humidity $(\mathrm{RH})$ also influences evaporative egg heat loss, and consequently, embryonic or fetal temperature (Decuypere et al., 2002; Molenaar et al., 2010). As the amount of energy required to evaporate water is $2.26 \mathrm{~kJ}$, eggs lose $2.26 \mathrm{~kJ}$ energy as heat per gram of evaporated water. Thus, the lower is the relative humidity inside the setter room, the greater is the loss of water by the egg and, therefore, its heat loss. This indicates that eggs incubated at low or high $\mathrm{RH}$ conditions may require different incubation temperatures to maintain the same embryo temperature (van der Pol et al., 2013), as both incubation relative humidity and temperature affect water vapor diffusion through the eggshell (Figure 2). Van der Pol et al. (2013) obtained higher hatchability in broiler eggs incubated at 55-60\% RH when eggshell temperature was maintained at $37.8^{\circ} \mathrm{C}$. Boleli \& Aidar (2013) determined that $36^{\circ} \mathrm{C}$ and $60 \% \mathrm{RH}$ are the optimal conditions for the incubation of red-winged tinamou (Rhynchotus rufescens) eggs.

Evaporative water loss around $12-14 \%$ relative to initial egg weight provide optimal hatchability (Tullett, 1981; Peebles, 1986). There is a consensus among studies that egg water loss should be approximately
$12-14 \%$ of the initial egg weight. The following optimal air relative humidity in the setter room were determined: 40-70\% for domestic chicken eggs (Gallus gallus) incubated at $37.8^{\circ} \mathrm{C}$ (Lundy, 1969); $55 \%$ for turkey (Meleagris gallopavo) eggs $(89.1 \mathrm{~g})$ incubated at $37.5^{\circ} \mathrm{C}$ (Meir et al., 1983.); 61-65\% until the $20^{\text {th }}$ day and $70-73 \%$ after the $21^{\text {st }}$ day of incubation for bobwhite quail (Colinus virgianus) eggs weighing approximately $12 \mathrm{~g}$ and incubated at $37.5^{\circ} \mathrm{C}$ (Kealy, 1969; Krueger, 1972; Wilson et al., 1975); and 20 to $25 \%$ until the $38^{\text {th }}$ day and 40 to $50 \%$ from $39^{\text {th }}$ day at $36.6^{\circ} \mathrm{C}$ for ostrich (Struthio camellus) eggs weighing 1.406 to $1.525 \mathrm{~g}$ (Horbanczuk et al., 1999; Kontecka et al., 2011). The majority of bird eggs loses $15 \%$ to $18 \%$ of its initial mass during incubation (Ar \& Rahn 1980; Drent, 1970, Ar et al., 1974).

The current commercial setter models allow controlling egg weight loss during incubation by monitoring egg tray weight loss. However, the efficacy of this control depends on the knowledge of egg water loss during pre-incubation period (especially during the storage period) and on the homogeneous distribution (weight or size) of the eggs in the setter trays.

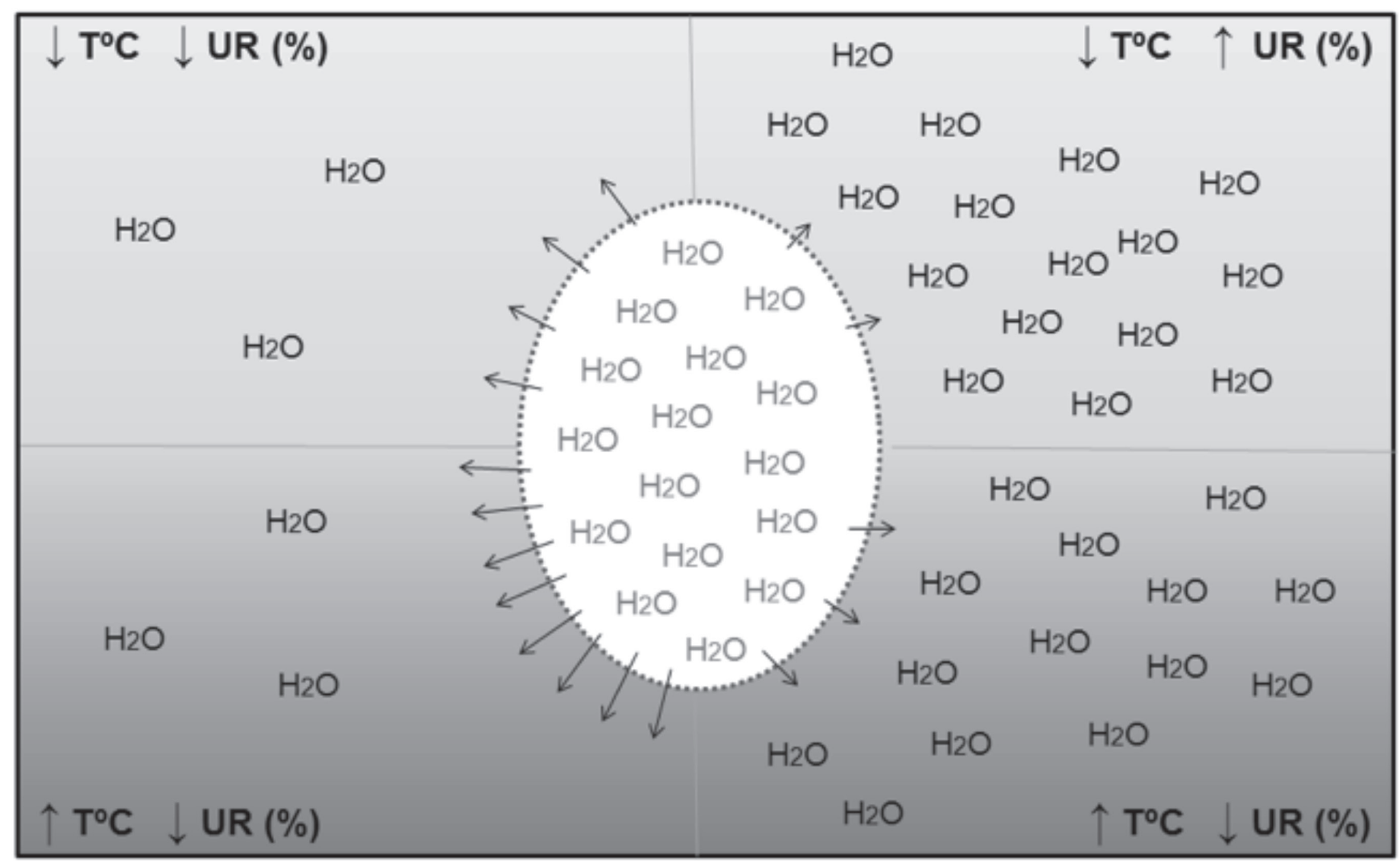

Figure 2 - Changes in the egg water loss during incubation with temperature $(T)$ and relative humidity (RH). 


\section{Egg turning, egg position, and ventilation}

The associated effects of egg turning, egg position, and ventilation influence several processes, including gas exchange and heat transfer between the eggs and the external environment, egg water loss, adhesion of the embryo to the extra-embryonic membrane structures (corium, amnion and allantois), and nutrient availability.

Egg turning is a natural behavior of birds during incubation, and therefore, this practice was included in the artificial incubation process. Egg turning allows the diffusion of gases inside the eggs and between the eggs and the external environment. It is critical particularly during the first week of incubation, due to the long distance between the embryo and the shell, and to the high albumen density. During this period, the embryo depends on the diffusion of gases through the eggshell and the albumen to obtain $\mathrm{O}_{2}$ and eliminate $\mathrm{CO}_{2}$, because the embryo develops on the yolk surface and gases are exchanged directly by the embryonic cells. After the emergence of the circulatory system ( $36 \mathrm{~h}$ of incubation) and the formation of the amniotic cavity and yolk vascularization, gases are exchanged through the vitelline vessels. The allantois begins to protrude out of the embryo body around days 3-4 of incubation, and continues to grow in size, surrounding the amniotic cavity, where the fetus develops. As both fetus and allantois grow, the allantois comes closer to the eggshell, reducing the distance traveled by the gases and allowing gas exchange via allantoic vessels by diffusion through the eggshell pores. Gas exchange through the allantoic arteries and veins begins on days 11-12 of incubation. By days 13-14 of incubation, fetal metabolic heat production increases, and egg turning aids the circulation of air in the inner surface of the egg (external shell membrane) and air chamber, and allows heat loss by conduction, convection, and evaporation. However, egg turning is also important to prevent dehydration and incorrect embryo development (Wilson, 1991). Moreover, egg turning moves nutrients, facilitating their absorption (Brinsea, 2006).

Egg turning is not as simple as it may seem. Egg turning frequency, axis of setting, angle, and plane of rotation influence in-ovo development, which may affect hatchability and chick quality (Wilson, 1991). Landauer (1967) demonstrated that chicken hens turned eggs approximately 96 times daily during natural incubation. Kaltofen \& Ubbels (1954) and Kaltofen (1956) showed that eggs turned 24 times per day (every hour) presented higher hatchability compared with eggs turned less frequently. Years later, Wilson (1990) observed that high egg-turning frequency (96 times/day or turning every 15 minutes) improves inovo development and hatchability. However, turning every 15 minutes is operationally difficult and increases equipment maintenance costs, and therefore, it is not applied in commercial settings.

The effect of egg turning rate on in-ovo development is also related to the tilt angle of the eggs. According to French (1997), normal embryo development requires eggs to be rotated 90 degrees every hour. This is achieved by horizontally tilting the eggs (horizontal setters) or the trays (vertical setters) over a $45^{\circ}$ angle from side to side (Figure 3 ). This is the angle that best fits the operational conditions of commercial setters, according Elibol \& Braket (2006) and Tona et al. (2005). Neves (2005), however, recommends that eggs should be horizontally turned 24 times daily at $20^{\circ}-45^{\circ}$ angles. In commercial hatcheries, broiler breeder eggs are turned $45^{\circ} \pm 5^{\circ}$ per hour until day 18 of incubation. Eggs are submitted to circular movements because the chorioallantoic membrane may break, causing embryonic mortality (Brito, 2006). Chicks hatched from eggs that turned at $45^{\circ}$ angle were heavier and presented lighter dry residual yolk (Cutchin et al., 2009). Egg-turning failures may reduce the formation of embryonic fluids, as well as the formation and growth of embryonic annexes, hindering embryonic and fetal development (Robinson, 2013).

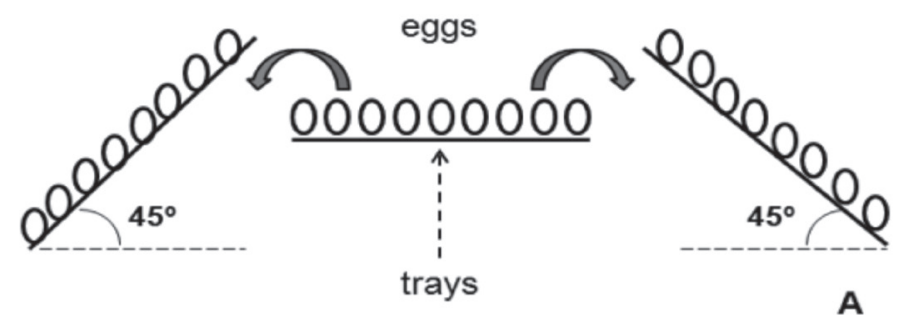

A

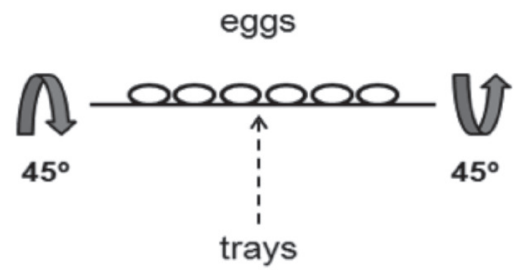

Figure 3 - Egg turning in vertical (A) and horizontal (B) incubators (adapted from Alvarado Mora, 2008)

Similar to natural conditions, eggs incubated in horizontal setters are set in a horizontal position. However, differences in egg size (jumbo, extra-large, medium, small) and egg shape (pointed, normal, 
or round) may change its position, impairing in-ovo development. The position of the eggs in the setter is critical for the formation of the air chamber, which irregular position and size may prevent internal pipping (Deeming, 1989), and result in in-ovo mortality when the chicks do not perform direct eggshell pipping. In addition, the correct position of the egg in the setter allows adequate gas exchange through the shell during incubation (Rondon \& Murakami, 1998). In vertical setters, eggs should be set with the large end up, i.e., where the air chamber is located, thereby allowing gas exchange between the egg and the environment. According to North \& Bell (1990), up to $4 \%$ of eggs are set in the wrong position, i.e., with the large end down, resulting in embryonic oxygen deficit and delayed metabolism. Wrong positioning of the eggs at setting may be related to slightly more rounded shape of the eggs, impairing the formation of the air chamber, and consequently, internal pipping.

Air renewal in the setter room is also essential in artificial egg incubation (Kornfeld et al., 2004). The fans in the setter room have two main functions: (i) to allow the intake of fresh air and removal of already circulated air, and (ii) to provide uniform air flow over the eggs, creating a homogeneous microclimate inside the setter that promotes adequate heat transfer, gas exchange, and water loss between the eggs and the incubation environment. The levels of $\mathrm{CO}_{2}$ inside the setter room should not exceed $0.4 \%$ (Cobb, 2008). Sotherland et al. (1987) state that setter room ventilation should be able to reduce the heat transfer coefficient in the beginning of incubation to heat the eggs, and to increase it at the end to allow egg heat loss. Therefore, air renewal in the setter room is essential for the removal of excessive $\mathrm{CO}_{2}$ and heat produced by the eggs, and for the restoration of $\mathrm{O}_{2}$ levels (Calil, 2007). On the other hand, air speed within the setter room may influence in-ovo development: an air velocity of $2 \mathrm{~m} / \mathrm{s}$ results in a $0.5-1{ }^{\circ} \mathrm{C}$ difference between air and egg temperatures, while $0.5 \mathrm{~m} / \mathrm{s}$ promotes a difference of $1-2.5^{\circ} \mathrm{C}$, which has strong effects the embryo development, resulting in weak hatchlings that may be unable to get out of the eggshell (Meijerhof and van Beek, 1993).

\section{Air quality: $\mathrm{O}_{2}$ and $\mathrm{CO}_{2}$ concentrations}

Maintaining of adequate $\mathrm{O}_{2}$ and $\mathrm{CO}_{2}$ concentrations in the setter room is essential for efficient gas exchange between the eggs and the incubation environment. As previously mentioned, the diffusion of $\mathrm{O}_{2}$ into the eggs and diffusion of $\mathrm{CO}_{2}$ and $\mathrm{H}_{2} \mathrm{O}$ out of eggs depends on the presence of pores in the eggshell and the gas concentration gradient between the internal and external environment of the eggs. Moreover, gas diffusion rate can be influenced by the physical characteristics of the eggs (surface area, pore number and geometry) and incubation conditions. In this context, larger egg surface areas, higher pore number and diameter, and thinner eggshells increase the rate of gas exchange between the eggs and the environment. This indicates that large eggs (typically laid by older hens) present greater gas exchange potential than small eggs (laid by young hens) (Morita et al., 2009). Gas diffusion increases with increasing temperature, according to the principles of physics. This means that the diffusivity of water vapor and gases through the eggshell increases as the incubation temperature increases (Booth \& Seymour, 1987; Morita et al., 2009).

Determining the optimal concentration of gases for egg hatching eggs is not an easy task, because all factors that affect gas diffusion must be considered. Furthermore, it is essential to take into account embryonic and fetal growth rate is different between large and small eggs, and therefore, have different metabolic rates. In addition, the increasing energy requirements of the embryos as they develop mean that the optimal concentration of gases inside the setter room also changes during incubation. This indicates that, although it is possible to establish optimal $\mathrm{O}_{2}$ and $\mathrm{CO}_{2}$ concentrations for egg incubation, from a practical perspective these concentrations can only be achieved in single-stage incubation. When establishing the optimal gas concentrations in the setter room required to optimize the incubation process, the effects of hypoxia and hypercapnia on embryonic and fetal development need to be considered.

Although setter rooms are provided with air renewal systems, the concentration of gases is determined by the quality of the atmospheric air where the hatchery is geographically located. The atmospheric concentrations of $\mathrm{O}_{2}$ and $\mathrm{CO}_{2}$ is the same at all altitudes $(21 \%$ and $0.03 \%$ at sea level, respectively). However, at higher altitudes, the air has fewer oxygen molecules and lower partial pressure of $\mathrm{O}_{2}(1.0 \%$ less for each $500 \mathrm{~m}$ increase) due to the decrease in barometric partial pressure. Egg incubation in high altitude areas (over 600 meters above sea level) increases late embryonic mortality and reduces hatchability and hatchling weight due to reduced $\mathrm{O}_{2}$ partial pressure (Schmidt-Nielsen, 2010; Sahan et al., 2011), which creates a hypoxic or a hypercarpnic environment (Coleman, 1986; Bagley \& Christensen 1989; Mauldin \& Buhr, 1991; Sahan et al., 2011.). Although the lower partial pressure 
of $\mathrm{O}_{2}$ leads to compensatory physiological responses (Tazawa; et al., 1971; Ruijtenbeek et al., 2000), these are not sufficient to restore normal embryonic and fetal development.

Hypoxia during incubation has different effects on poultry embryonic and fetal development, depending on the period of embryo development, and on the duration and level of hypoxia (Azzam et al., 2007; Ferner \& Mortola, 2009; Zhang \& Burggren, 2012). Interestingly, Bahadoran et al. (2010) found that early hypoxia (incubation at $1800 \mathrm{~m}$ above sea level until embryonic day 10), followed by normoxia (incubation at sea level) reduces the duration of incubation, reduces the incidence of ascites, and improves the feed conversion ratio and body weight of 42 - $d$-old broilers reared in normoxia. All these results indicate that the first half of incubation (1-11 days of incubation) is the critical window for the adverse effects of hypoxia on in-ovo development, while the second half (from day 12 until hatching) is the critical window for the compensatory response of organs to hypoxia. The effects of early hypoxia are related with the increase in the gas exchange surface, particularly to the increase in chorioallantoic mass and to angiogenesis (Chan \& Burggren, 2005; Azzam \& Mortola, 2007; Zhang \& Burgreen, 2012), as well as with increased pulmonary angiogenesis and vascularization (Lewallen \& Burggren, 2015).

Relative to hypercapnia, $\mathrm{CO}_{2}$ levels in the setter equal to $1 \%$ or higher on days 1-4 (Taylor et al., 1956), $3 \%$ on days $5-8$, and higher than $6 \%$ on days $9-12$ of incubation (Taylor et al., 1965, 1966) decrease hatchability. However, other studies showed that the gradual increase of $\mathrm{CO}_{2}$ concentration until day 10 of incubation promoted embryonic growth, reduced incubation time, increased hatchability (Gildersleeve et al., 1983; De Smit et al., 2006; Bruggeman et al., 2008), and improved chick quality (Tona et al., 2007; De Smit et al., 2006, 2008). These results were associated with the development of the circulatory system and increased production of red blood cells, allowing greater $\mathrm{O}_{2}$ uptake and energy conservation (Tazawa et al., 2002; Decuypere et al., 2006; Habermann et al., 2008; Verhoelst et al., 2011).

Despite the considerable significant scientific knowledge on the effects of hypoxia and hypercapnia on in-ovo development acquired in the last few years, from the practical perspective, the optimal $\mathrm{O}_{2}$ and $\mathrm{CO}_{2}$ levels in the setter rooms during commercial incubation still need to be determined.

\section{Incubation temperature}

Although the interaction among several physical agents during incubation influences in-ovo development, temperature has the strongest influence (Freeman \& Vince, 1974; Decuypere \& Michels, 1992; Meijerhof, 2009), because it can hinder, promote, or maintain embryonic and fetal development, as well as determine its rate and duration. Eggs are submitted to different temperatures from reception of the eggs at the hatchery until hatching. During storage, temperature is reduced to delay embryonic development. Subsequently, eggs are heated to reactivate embryonic development immediately before setting. During incubation, the temperature must be maintained to ensure the production of healthy chicks. In addition, the manipulation of incubation temperature allows anticipating or delaying hatch according to the demand for chicks.

Optimal incubation temperatures result in high hatchability of healthy chicks with good post-hatch performance. In this context, deviations need to be prevented because they can impair embryonic development (Romanoff, 1960), hatchability (Deeming \& Ferguson, 1991; Wilson, 1991; Decuypere \& Michels, 1992), hatchling quality (Lourens et al., 2005, 2007, Hulet et al., 2007) and post-hatch performance (Lundy, 1969; Decuypere, 1984; Wilson, 1991). The optimal temperature for poultry egg incubation is closer to the maximum temperature tolerated by the birds (high LT100) than of the minimum temperature (low LT100). Therefore, slight deviations above the recommended incubation temperatures are more detrimental to inovo development than similar deviations below those temperatures. High incubation temperatures have negative impacts on chick heart weight (Wineland et al., 2000; Leksrisompong et al., 2007; Lourens et al., 2007), on bone development (Oviedo-Rondon et al., 2009a, b; van der Pool et al., 2014), and on the immune system (DuRant et al., 2012), predisposing chicks to ascites, leg problems, and immune deficiencies, respectively.

During natural incubation, eggs are often exposed to temperature fluctuations in the nest, which may be caused by environmental temperature variations or changes in the attention hens direct to the eggs. Before the complete development of the chorioallantoic membrane, around day 12 of incubation (Tullett \& Deeming, 1987), the embryo responds to the temperature gradient between the egg region in contact with the hen and the part of the egg in contact with the nest material, directing the blood flow to the colder 
region, regulating its internal temperature (Tzschentke \& Nichelmann, 1997). After the complete development of the chorioallantoic membrane, the embryo is able to redistribute heat through its bloodstream (Turner, 1997), which allows regulating its temperature within certain limits. Both the direction of the heat flow and heat distribution through the bloodstream make the embryo less dependent of climate conditions around the egg. This shows that the embryo is able to react to minor temperature fluctuations inside the egg, and that it attempts to regulate its internal temperature within a very narrow range (Tzschentke \& Nichelmann, 1997). Based on these findings, studies were carried out to assess the effects of incubation temperature on embryo temperature, thermal manipulation during incubation, and in-ovo injection of the anti-stress nutrients, such as vitamin C, as means to induce possible thermal adaptation of poultry during rearing or to promote phenotypic changes to meet specific objectives (Sgavioli et al., 2013, 2015, 2016; Ferreira et al., 2015; Almeida et al., 2016; Morita et al., 2016 a,b).

\section{Eggshell temperature}

Although embryonic and/or fetal temperature inside the egg is not identical to that of the egg surface, for practical reasons, eggshell temperature (EST) has been used as an indicator of embryo/fetus temperature (French, 1997; Lourens et al., 2005; Joseph et al., 2006; Hulet et al., 2007, Molenaar et al., 2010; Walstra et al., 2010), due to the small differences between those temperatures, usually of $0.1-0.2^{\circ} \mathrm{C}$ (Meijerhof \& Van Beek, 1993; French, 1997).

In chicken eggs, eggshell temperature remains low during the first week of incubation and increases during the second week, reaching a temperature plateau around day 14-15 of incubation (French, 2007). It was demonstrated that eggshell temperature increases from the second third of incubation at 36$39^{\circ} \mathrm{C}$ incubation temperature (Sgavioli et al., 2015; Almeida et al., 2016; Morita et al., 2016). This increase is related with the greater metabolic heat production by the fetus during this high growth rate phase (Lourens et al., 2006, 2007). After internal pipping, around day 19 of incubation, chorioallantoic gas exchange is gradually replaced by pulmonary respiration and, consequently, heat production by the fetuses of broiler chickens nearly doubles (Rahn, 1981; Janke et al., 2004). As mentioned above, according to the laws of thermodynamics, heat is transferred between the eggs and the incubation environment down a thermal gradient, i.e., always from the warmer to colder region. Under optimal incubation temperature (around $37.5-37.8^{\circ} \mathrm{C}$ ), eggshell temperature remains lower than the setter room temperature during the first week, starts to increase in the second week, and it is higher than the setter room temperature during the last week of incubation (French, 2007; Sgavioli et al., 2015). This indicates that eggs incubated under those temperatures need to gain heat in the beginning and to lose it during the last week of incubation, respectively. Therefore, incubation temperature needs to be set according to requirements of the embryo and fetus to optimize incubation efficiency.

Constant eggshell temperature during incubation results from a balance between embryo or fetus heat production and heat transfer between the egg and the environment (Meijerhof \& van Beek, 1993). In order to maintain an optimal eggshell temperature of $37.5-38.0{ }^{\circ} \mathrm{C}$ during the entire incubation period, setter room air temperature must be higher than 37.5 to $38.0^{\circ} \mathrm{C}$ during the first days of incubation and reduced from day 9 of incubation onwards (French, 1997; Lourens et al., 2005, 2006; Yahav et al., 2009). Maintaining constant eggshell temperature at 37.5$38.0{ }^{\circ} \mathrm{C}$ throughout incubation period promotes high hatchability and good chick quality (Lourens et al., 2005, 2007; Joseph et al., 2006; Leksrisompong et al., 2007). These results led companies to develop egg setter with temperature control based on eggshell temperature. From a practical point of view, however, it should be noted that only single-stage incubators allow reducing incubation temperature to maintain constant eggshell temperature.

Constant eggshell temperature during incubation may be achieved by reducing of setter room air temperature during the second half of in-ovo development due to the greater eggshell heat loss to the setter room air. However, recent studies (data not published) suggest that eggshell temperature may not be the most important factor for the optimization of in-ovo development, and consequently, of incubation results, and may change the current concepts of optimal incubation conditions.

\section{Thermal manipulation during incubation}

Embryo thermal manipulation or changes in incubation temperature have been studied by several research groups to determine an embryonic development window during which thermal manipulation may promote the acquisition of specific characteristics. The main objectives are to increase chicken thermo tolerance during rearing or to modulate commercially important characteristics, such as immune response, fat deposition, etc. (Lourens et 
al., 2005; Joseph et al., 2006; Molenaar et al., 2010; Walstra et al. 2010; Ipek et al., 2014; Almeida et al., 2015; Ferreira et al., 2015; Sgavioli et al., 2015; Morita et al., 2016). Researchers have applied different types of thermal manipulation, in terms of intensity, frequency, duration, and embryonic development period (Tables 1-3). The results obtained until now have shown that fetal development (from days 8-9 of incubation) seem to be the most promising period for the application thermal manipulation, and that are other possible windows within this period or not, according to the target system, organ, or tissue. In addition, those studies have generated data that provide new insights about optimal incubation conditions and about the potential responses of poultry to variations in these conditions. Our research group analyzed the effects of moderate thermal manipulation $\left(36^{\circ} \mathrm{C}\right.$ and $\left.39^{\circ} \mathrm{C}\right)$ from day 13 of incubation until hatch, and found that egg incubation at $39^{\circ} \mathrm{C}$ reduced hatchling adiposity (Almeida et al., 2015). Thermal manipulation during incubation changes thermal preference of chickens. Broiler chicks incubated at high temperature $\left(1{ }^{\circ} \mathrm{C}\right.$ above the optimal temperature) preferred higher rearing temperature during the first three weeks of age, and presented greater tolerance to heat stress until the fourth week than those incubated at optimal $\left(37.5^{\circ} \mathrm{C}\right)$ or low $\left(36^{\circ} \mathrm{C}\right)$ temperatures (Morita et al., 2016). These authors also found that high incubation temperature $\left(1.5^{\circ} \mathrm{C}\right.$ higher than the optimal temperature) from day 13 until hatch induces changes in the skin characteristics related with heat loss, such reduced thickness and greater irrigation (Morita et al., 2016 b), which may account for the preference of these birds for warmer environments (Morita et al., 2016). In our view, these results demonstrate that, opposite to what it was previously known, birds physiologically respond to environmental responses to temperature variations already during the fetal stage.

In recent years, in-ovo nutrition has also been applied to manipulate phenotypic and growth characteristics birds submitted to heat stress during rearing. Ferreira et al. (2015) showed that association of in-ovo injection of vitamin C (anti-stressor) with high incubation temperature $\left(39^{\circ} \mathrm{C}\right)$ reduces the deleterious effects of high environmental temperature on the meat quality of broilers. Sgavioli et al. (2015), on the other hand, showed that high incubation temperature, with or without in-ovo injection of vitamin $C$, induces

Table 1 - Overview of the effects of incubation temperature manipulation onhatchability, incubation length, and chickcharacteristics.

\begin{tabular}{|c|c|c|c|c|c|c|c|c|c|}
\hline \multirow[b]{2}{*}{ Author } & \multicolumn{3}{|c|}{ Incubation Treatments } & \multirow[b]{2}{*}{ Hatchability } & \multirow{2}{*}{$\begin{array}{c}\text { Incubation } \\
\text { duration }\end{array}$} & \multicolumn{4}{|c|}{ Chick characteristics } \\
\hline & Temperature & Period & Duration & & & $\begin{array}{c}\text { Body } \\
\text { temperature }\end{array}$ & $\begin{array}{c}\text { Body } \\
\text { weight }\end{array}$ & $\begin{array}{l}\text { Yolk sac } \\
\text { weight }\end{array}$ & Quality \\
\hline \multirow[t]{4}{*}{ Yalçin \& Siegel (2003) } & $36.9^{\circ} \mathrm{C}$ & E0-E8 & 6 h/day & $x$ & $x$ & $x$ & $=$ & $x$ & $x$ \\
\hline & $39.6^{\circ} \mathrm{C}$ & & & $x$ & $x$ & $x$ & $=$ & $x$ & $x$ \\
\hline & $36.9^{\circ} \mathrm{C}$ & E10-E18 & & $x$ & $x$ & $x$ & $=$ & $x$ & $x$ \\
\hline & $39.6^{\circ} \mathrm{C}$ & & & $x$ & $x$ & $x$ & $=$ & $x$ & $x$ \\
\hline \multirow[t]{4}{*}{ Yahav et al. (2004b) } & $39.5^{\circ} \mathrm{C}$ & E8-E10 & 3 h/day & $=$ & $x$ & $x$ & $=$ & $x$ & $x$ \\
\hline & & E16-E18 & & $\uparrow$ & $x$ & $x$ & $=$ & $x$ & $x$ \\
\hline & $41.0^{\circ} \mathrm{C}$ & E8-E10 & 3 h/day & $=$ & $x$ & $x$ & $=$ & $x$ & $x$ \\
\hline & & E16-E18 & & $=$ & $x$ & $x$ & $=$ & $x$ & $x$ \\
\hline \multirow[t]{4}{*}{ Collin et al. (2005) } & $39.5^{\circ} \mathrm{C}$ & E16-E18 & 3 h/day & $=$ & $x$ & $=$ & $=$ & $x$ & $x$ \\
\hline & & & 6 h/day & $=$ & $x$ & $=$ & $=$ & $x$ & $x$ \\
\hline & & & 12 h/day & $=$ & $x$ & $=$ & $=$ & $x$ & $x$ \\
\hline & & & 24 h/day & $=$ & $x$ & $=$ & $=$ & $x$ & $x$ \\
\hline \multirow[t]{3}{*}{ Collin et al. (2007) } & $39.5^{\circ} \mathrm{C}$ & E8-E10 & 3 h/day & $\uparrow$ & $x$ & $\downarrow$ & $=$ & $x$ & $x$ \\
\hline & & $\mathrm{E} 16-\mathrm{E} 18$ & & $\uparrow$ & $x$ & $\downarrow$ & $=$ & $x$ & $x$ \\
\hline & & Both $\mathrm{E}$ & & $\downarrow$ & $x$ & $=$ & $=$ & $x$ & $x$ \\
\hline \multirow[t]{2}{*}{ Piestun et al. (2008) } & $39.5^{\circ} \mathrm{C}$ & E7-E16 & 12 h/day & $=$ & $x$ & $\downarrow$ & $=$ & $x$ & $x$ \\
\hline & & & 24 h/day & $\downarrow$ & $x$ & $\downarrow$ & $\downarrow$ & $x$ & $x$ \\
\hline Tona et al. (2008) & $39.5^{\circ} \mathrm{C}$ & E16-E18 & 3 h/day & $=$ & $\uparrow$ & $\downarrow$ & $=$ & $x$ & $x$ \\
\hline \multirow[t]{2}{*}{ Shinder et al. (2011) } & $15^{\circ} \mathrm{C}$ & E18-E19 & $2 \times 30 \mathrm{~min}$ & $=$ & $x$ & $=$ & $=$ & $x$ & $x$ \\
\hline & & & $2 \times 60 \mathrm{~min}$ & $=$ & $x$ & $\downarrow$ & $=$ & $x$ & $x$ \\
\hline Loyau et al. (2013) & $39.5^{\circ} \mathrm{C}$ & E7-E16 & 12 h/day & $=$ & $x$ & $\downarrow$ & $=$ & $x$ & $x$ \\
\hline \multirow[t]{2}{*}{ Almeida et al. (2015) } & $36^{\circ} \mathrm{C}$ & From E13 & 24 h/day & $=$ & $\uparrow$ & $=$ & $=$ & $=$ & $=$ \\
\hline & $39^{\circ} \mathrm{C}$ & & & $\uparrow$ & $=$ & $=$ & $=$ & $=$ & $\downarrow$ \\
\hline
\end{tabular}

E; embryonic day. =; no significant difference between the control and the thermally-manipulated groups. $\uparrow$ and $\downarrow$ : higher and lower values determined in thermally-manipulated groups compared with the control group, respectively. $\mathrm{X}$ : not reported. 
conductance), egg storage conditions (temperature, relative humidity, air velocity) and duration, and the incubation conditions (temperature, relative humidity, egg turning and position at setting, and air velocity and gas concentrations). The maternal effects on the physical exchanges show that the optimal storage and incubation conditions vary with breeder age and egg weight. However, optimal storage and incubation conditions as a function of egg weight or weight range still need to be established. Although this proposal seems to be unrealistic at first sight, it may be feasible as the control systems of incubation physical conditions (e.g., controlling egg weight loss, setting incubation temperature according to the eggshell temperature) are further technologically developed, allowing their easier and quicker determination. In addition, incubation conditions, which are essential for maximizing the production efficiency of hatcheries, may be optimized.

\section{REFERENCES}

Almeida VR, Morita VS, Sgavioli S, Vicentini TI, Castiblanco DMC, Boleli IC. Incubation temperature manipulation during fetal development reduces adiposity of broiler hatchlings. Poultry Science 2016;95(2):316324.

Alvarado Mora L. Processo de incubação artificial de ovos: desenvolvimento de sistemas de medição de temperatura e massa [dissertação]. Campinas (SP): Universidade Estadual de Campinas; 2008.

Ar A, Paganelli CV, Reevers RB, Green DG, Rahn H. The avian egg: water vapor conductance, shell thickness and functional pore area. Condor 1974;76:153-158.

$\operatorname{Ar} \mathrm{A}$, Rahn H. Water in the avian egg: overall budget of incubation. American Zoologist 1980;20:373-384

$\operatorname{Ar}$ A. Roles of water in avian eggs. In: Deeming DC, Ferguson MWJ. Egg Incubation: its effects on embryonic development in birds and reptiles. Cambridge: Cambridge University Press; 2004. p.229-243.

AviSite. Carnes: a evolução em uma década, segundo a FAO [cited 2015 Dec 4]. Available from: http://avisite.com.br/noticias/index. php?codnoticia $=15871$.

Azzam MA, Mortola JP. Organ growth in chicken embryos during hypoxia: implications on organ "sparing" and "catch-up growth". Respiratory Physiology and Neurobiology 2007;159:155-162.

Azzam MA, Szdzuy K, Mortola JP. Hypoxic incubation blunts the development of thermogenesis in chicken embryos and hatchlings. American Journal of Physiology 2007;292:2373-2379.

Bagley LG, Christensen VL. Comparisons of turkey embryos incubated in tenuous or dense gas environments--II. Organ growth. Organ growth. Comparative Biochemistry Physiology 1989;93(2):451-454.

Bahadoran S, Hassanzadeh M, Zamanimoghaddam AK. Effect of chronic hypoxia during the early stage of incubation on prenatal and postnatal parameters related to ascites syndrome in broiler chickens. Iranian Journal of Veterinary Research 2010;11(1):64-71.

Boerjan M. Earley embriogenesis of the chick. In: Post Graduation Course in Incubation Biology and Management. Wageningen: University of Wageningen; 2006.
Boleli IC, Queiroz SA. Effects of incubation temperature and relative humidity on embryonic development in eggs of red-winged Tinamou (Rhynchotus rufescens). International Journal of Poultry Science 2012;11(8):517-523.

Booth DT, Seymour RS. Effect of eggshell thinning on water vapour conductance of malleefowl (Leipoa ocellata) eggs. Condor 1987:89:453-459.

Brinsea. Incubation Handbook. 2006 [cited 2016 Abr 01]. Available from: http://www.brinsea.com/pdffiles/Brinsea_Handbook.pdf.

Brito AB. Problemas microbiológicos na incubação artificial [cited 2016 Abr 01]. Disponível em: http://www.polinutri.com.br/conteudo_artigos_ anteriores_agosto_06.htm

Brody S. Bioenergetics and growth. New York: Reinhold; 1945

Bruggeman V, De Smit L, Tona K, Everaert N, Witters A, Debonne M, et al. Changes in albumen $\mathrm{pH}$ due to higher $\mathrm{CO}_{2}$ concentrations during the first ten days of incubation. Poultry Science 2008;87:734-739.

Calil TAC. Princípios básicos de incubação. Anais da Conferência Apinco de Ciência e Tecnologia Avícolas; 2007; Santos, São Paulo. Brasil. Campinas: FACTA; 2007

Chan T, Burggren WW. Hypoxic incubation creates differential morphological effects during specific developmental critical windows in the embryo of the chicken (Gallus gallus). Respiratory Physiology \& Neurobiology 2005; 145:251-263.

Coleman MA. Solving hatchability problems. Poultry International 1986;1215.

Collins CT, Lecory M. Analysis of measurements, weights and composition of Common and Roseate Tern eggs. Wilson Bulletin 1972;84:187-192.

Coob. Operação da máquina incubadora. In: Cobb-Vantress Brasil. Guia de manejo de incubação. Guapiaçu; 2008. cap. 4, p.8-12.

Cutchin HR, Wineland MJ, Christensen VL, Davis S, Mann KM. Embryonic development when eggs are turned different angles during incubation. Journal of Applied Poultry Research 2009;18:447-451

Davis TA, Shen SS, Ackerman R A. Embryonic osmoregulation consequences of high and low water-loss during incubation of the chicken egg. Journal of Experimental Zoology 1988;245(2):144-156.

De Smit L, Bruggeman V, Debonne M, Tona JK, Kamers B, Everaert N, et al. The effect of non-ventilation during early incubation on the embryonic development of chicks of two commercial broiler strains differing in ascites susceptibility. Poultry Science 2008;87:551-552.

De Smit L, Bruggeman V, Tona JK, Debonne M, Onagbesan O, Arckens $L$, et al. Embryonic developmental plasticity of the chick: Increased $\mathrm{CO}_{2}$ during early stages of incubation changes the developmental trajectories during prenatal and postnatal growth. Comparative Biochemistry and Physiology Part A 2006;145:166-175.

Decuypere $\mathrm{E}$. Incubation temperature in relation to postnatal performance in chickens. Archiv fur Experimentalle Veterinar Medizin 1984;38:439449 .

Decuypere $\mathrm{E}$, Michels $\mathrm{H}$. Incubation temperature as a management tool: a review. World's Poultry Science Journal 1992;48:27-38.

Decuypere E, Tona K, Bruggeman V, Bamelis F. The day-old chick: a crucial hinge between breeders and broilers. World's Poultry Science Journal 2001:57:127-138

Decuypere E, Onagbesan O, De Smit L, Tona K, Everaert N, Witters A, et al. Hypoxia and hypercapnia during incubation of chicken eggs: effects on development and subsequent performance. World's Poultry Science Journal 2006:62:486-487. 
Boleli IC, Morita VS, Matos Jr JB, Thimotheo M Almeida VR
Poultry Egg Incubation: Integrating and Optimizing Production Efficiency
Decuypere $E$, Bruggeman $\mathrm{V}$. The endocrine interface of environmental and egg factors affecting chick quality. Poultry Science 2007;86(5):10371042

Deeming DC. Characteristics of unturned eggs; critical period, retarded embryonic growth and poor albumen utilization. British Poultry Science 1989;30:239-249.

Deeming DC. Importance and evolution of incubation in avian reproduction. 1-7. In: Deeming DC, editor. Avian incubation;behaviour, environment and evolution. Oxford: University Press; 2002. p. 421

Deeming DC. Avian incubation, behaviour, environment, and evolution. Lincoln: Oxford University Press; 2002.

Deeming DC, Ferguson MWJ. Physiological effects of incubation temperature on embryonic development in reptiles and birds. In: Deeming DC, Ferguson MJW, editors. Egg incubation. Cambridge: Cambridge University Press; 2012. p.147-172.

Drent R. Functional aspects of incubation in the Herring Gull. Behaviour 1970;17(Suppl.):1-132

DuRant SE, Hopkins WA, Hawley DM, Hepp GR. Incubation temperature affects multiple measures of immunocompetence in young wood ducks (Aix Sponsa). Biology Letters 2012;8:108-111.

Elibol O, Braket J. Effect of egg turning angle and frequency during incubation on hatchability and incidence of unhatched broiler embryos with head in the small end of the egg. Poultry Science Association 2006;85:1433-1437

Ferner K, Mortola JP. Ventilatory response to hypoxia in chicken hatchlings; a developmental window of sensitivity to embryonic hypoxia. Respiratory Physiology and Neurobiology 2009;165:49-53.

Ferreira IB, Matos JB Junior, Sgavioli S, Vicentini TI, Morita VS, Boleli IC. Vitamin $C$ prevents the effects of high rearing temperatures on the quality of broiler thigh meat. Poultry Science 2015;94(5):8141-8151.

Freeman BM, Vince MA. Incubation requirements. In: Freeman BM, Vince $M A$, editors. Development of the avian embryo. London: Chapman and Hall; 1974.

French NA. Effect of short periods of high incubation temperature on hatchability and incidence of embryo pathology of turkey eggs. Brazilian Journal of Poultry Science 2000;41:377-382.

French NA. Modeling incubation temperature; the effects of incubator design, embryonic development, and egg size. Poultry Science 1997;76:124-133

Gildersleeve RP, Boeschen DP. The effects of incubator carbon dioxide level on turkey hatchability. Poultry Science 1983;62:779-784.

Hambermann F, Feske D, Tonhardt HE. Measurement in chick embryos using non-invasive technology. World's Poultry Science Journal 2008;64:605610.

Hamburger V, Hamilton $\mathrm{HL}$. A series of normal stages in the development of the chick embryo. Journal of Morphology 1951;88:91. Reprinted by Developmental Dynamics 1992;195:231-272.

Horbanczuk JO, Sales J, Celeda T, Zieba G. Effect of relative humidity in the hatchability of ostrich (Struthio camelus) eggs. Czech Journal of Animal Science 1999;44(7):303-307

Hulet RM, Gladys G, Meijerhof R, Meijerhof R, El-Shiekh T. Influence of egg shell embryonic incubation temperature and broiler breeder flock age on post hatch growth performance and carcass characteristics. Poultry Science 2007;86:408-412.

Ipek A, Sahan U, Baycan SC, Sozcu A. The effects of different eggshell temperatures on embryonic development, hatchability, chick quality, and first-week broiler. Poultry Science 2014;93:464-472.
Janke O, Tzschentke B, Boerjan M. Comparative investigations of heat production and body temperature in embryo $\mathrm{S}$ of modern chicken breeds. Avian and Poultry Biology Reviews 2004;15:191-196.

Joseph NS, Lourens A, Moran Jr ET. The effects of suboptimal eggshell temperature during incubation on broiler chick quality, live performance, and further processing yield. Poultry Science 2006;85:932-938.

Kaltofen, RS, Ubbels P. On the turning of eggs in artificial incubation. Animal Breeding Abstract 1954;22(1175):253.

Kaltofen RS. Het bruederij onderzoek te Beekbergen. Landbouwvoorlichting 1956;13:544- 550,

Kealy RD. Storage and incubation of game bird eggs. Proceedings of the $1^{\text {a }}$ Texas Comm. Game Bird Conference; 1969; Minnesota. Estados Unidos. Minneapolis: Universidade de Minnesota; 1969. p.42-57.

Kontecka H, Wonicka J, Witkiewicz K, Nowaczewski S. Laying, egg and hatchability caracteristics in ostrich (Struthio camelus)at different age. Foliabiologica 2011;59:3-4.

Kornfeld ME, Elmôr RA, Barbosa FW. A criação do avestruz. Caicara do Rio do Vento: Grupo Ostrich do Brasil; 2004. p.127-141.

Krueger WF. Maximizing hatchability in game bird operations. North American Game Breeders and Shooting Preserve Operators Association 1972;3:18-19

Landauer W. The hatchability of chicken eggs as influenced by environment and heredity [monograph 1]. Storrs: Agricultural Experiment Station Connecticut; 1967

Leksrisompong N, Romero-Sanchez H, Plumstead PW, Brannan KE, Brake J. Broiler incubation. 1. Effect of elevated temperature during late incubation on body weight and organs of chicks. Poultry Science 2007;86:2685-2691.

Lewallen MA, Burggren WW. Chronic hypoxia and hyperoxia modifies morphology and VEGF concentration of the lungs of the developing chicken (Gallus gallus variant domesticus). Respiratory Physiology and Neurobiology 2015;219:85-94.

Lourens A, van den Brand $H$, Meijerhof $R$, Kemp B. Effect of eggshell temperature during incubation on embryo development, hatchability, and posthatch development. Poultry Science 2005;84:914-920.

Lourens A, Molenaar R, van den Brand H, Heetkamp MJ, Kemp B. Effect of egg size on heat production and the transition of energy from egg to hatchling. Poultry Science 2006;85:770-776

Lourens A, van den Brand H, Heetkamp MJ, Meijerhof R, Kemp B. Effects of eggshell temperature and oxygen concentration on embryo growth and metabolism during incubation. Poultry Science 2007;86:21942199.

Lundy H.A review of the effects of temperature, humidity, turning and gaseous environment in the incubator on the hatchability of the hen's egg. In: Carter TC, Freeman BM, editors. The fertility and hatchability of the hen's egg. Edinburgh: Oliver and Boyd; 1969. p.143-176.

Mauldin DM, Buhr, JR, Wilson JL. Analysing hatch day breakout and embryonic mortality. Misset Misset International 1991;7(7):24-25.

Meijerhof R, vanBeek G. Mathematical modeling of temperature and moisture loss of hatching eggs. Journal of Theoretical Biology 1993:165:27-41.

Meijerhof R. Incubation principles; what does the embryo expect from us? Proceedings of the 20th Australian Poultry Science Symposium; 2009; Sydney, New South Wales. Australia: University of Sydney; 2009. p.106-110. 
Meir M, Ar A. Improving turkey poultry quality by correcting incubator humidity to match eggshell conductance. British Poultry Science 1987;28:337-342.

Molenaar R, Meijerhof R, Van Den Anker I, Heetkamp MJ, van den Borne JJ, Kemp B, et al. Effect of eggshell temperature and oxygen concentration on survival rate and nutrient utilization in chicken embryos. Poultry Science 2010;89:2010-2021.

Molenaar R, Reijrink I, Meijerhof R, Van den Brand H. Meeting embryonic requirements of broilers throughout incubation; a review. Revista Brasileira de Ciência Avícola 2010;12(3):137-148.

Morita VS, Boleli IC, Cargnelutti Filho A. Hematological values and body, heart and liver weights in male and female broiler embryos taken from eggs of young and old breeders. Brazilian Journal of Poultry Science 2009;11:19-27.

Morita VS, Boleli IC, Oliveira JA. Hematological and incubation parameters of chicks from young breeders eggs; variation with sex and incubation temperature. International Journal of Poultry Science 2010;9(6):606612.

Morita VS, Almeida VR, Matos Junior JB, Vicentini TI, van den Brand H, Boleli IC. Incubation temperature alters thermal preference and response to heat stress of broiler chickens along the rearing phase. Poultry Science 2016;95(8):1795-1804.

Morita VS, Almeida VR, Matos Junior JB, Vicentini TI, van den Brand $\mathrm{H}$, Boleli IC. Incubation temperature during fetal development influences morphophysiological characteristics and preferred ambient temperature of chicken hatchlings. Plos One 2016;11(5);e0154928.

Mortola, JP. Gas exchange in avian embryos and hatchlings. Comparative Biochemistry and Physiology a-Molecular \& Integrative Physiology 2009;153(4):359-377

Neves ACRS. Maximização do Fluxo operacional em incubatórios comerciais. Anais do $7^{\circ}$ Simpósio Goiano de Avicultura; $2^{\circ}$ Simpósio Goiano de Suinocultura; 2005; Goiânia, Goiás. Brasil: AVESUI CentroOeste; 2005. p. 46-53.

North MO, Bell DD. Commercial chicken production manual. 4th ed. New York: Van Nostrand Reinhold; 1990.

OECD. Food and Agriculture Organization of the United Nations [cited 2015 Dez 8]. Paris: OECD-FAO. 2015. Available from: http://dx.doi. org/10.1787/agr_outlook-2015-en.

Oviedo-Rondón EO, Wineland MJ, Funderburk S, Small J, Cutchin H, Mann $M$. Incubation conditions affect leg health in large, high-yield broilers. The Journal of Applied Poultry Research 2009a;18:640-646.

Oviedo-Rondón EO, Wineland MJ, Small J, Cutchin H, McElroy A, Barri $A$, et al. Effect of incubation temperatures and chick transportation conditions on bone development and leg health. The Journal of Applied Poultry Research 2009b;18:671-687.

Panda B, Singh, RP. Developments in processing quail meat and eggs. World's Poultry Science Journal 1990;46:219-234.

Paniago M. Artificial incubation of poultry eggs - 3,000 years of history. CEVA Animal Health Asia Pacific 2005;(2):1-3

Rahn H. Gas exchange of avian eggs with special reference to turkey eggs. Poultry Science 1981;60:1971-1980.

Reinhart BS, Hurnik GI. Traits affecting the hatching performance of commercial chicken broiler eggs. Poultry Science 1984;63:240-245.

Robison FE, Fasenko GM, Renema RA. Optimizing chick production in broiler breeders. Alberta: Poultry Research Centre; 2013. v.1.
Romanoff AL, Romanoff AJ. The avian egg. New York: John Wiley and Sons; 1949

Romanoff AL. The avian embryo; structural and functional development. New York: Macmillan; 1960.

Rondón EOO, Murakami AE. Fatores que interferem no desenvolvimento embrionário e seus efeitos nos problemas metabólicos pós-eclosão em frangos de corte. Acta Scientiarum 1998;20(3):373-382

Ruijtenbeek K, Le Noble FAC, Janseen GMJ, Kessels CGA, Fazzi GE, Blanco $C E$, et al. Chronic hypoxia stimulates periarterial sympathetic nerve development in chicken embryos. Circulation 2000;102:2892-2897.

Sahan U, Ipek A, Yilmaz-Dıkmen B, Aydin C, Kederlı E. Effect of oxygen supplementation in the hatcher at high altitude on the incubation results of broiler eggs laid at low altitude. British Poultry Science $2011 ; 52(3): 388-394$

Schmidt-Nielsen K. Respiração. In. Schmidt-Nielsen K. Fisiologia animal: adaptação e meio ambiente. $5^{a}$ ed. Santos: Livraria e Editora; 2010. p. 5-64

Sgavioli S, Borges LL, Almeida VR, Thimotheo M, Oliveira JA, Boleli IC. Egg injection of ascorbic acid stimulates leukocytosis and cell proliferation in the bursa of Fabricius. International Journal of Poultry Science $2013 ; 12(8) ; 464-472$.

SgavioliS, Matos Júnior JB, Borges LL, Praes MFFM, Morita VS, Zanirato GL, et al. Effects of ascorbic acid injection in incubated eggs submitted to heat stress on incubation parameters and chick quality. Revista Brasileira de Ciências Avícolas 2015;17:181-189.

Sgavioli S, Domingues CHF, Santos ET, Quadros TCO de, Borges LL, Garcia RG, et al. Effect of in-ovo ascorbic acid injection on the bone development of broiler chickens submitted to heat stress during incubation and rearing. Revista Brasileira de Ciências Avícolas 2016;18(1):153-162.

SNA News - Boletim Semanal da Sociedade Nacional de Agricultura. FAO? produção mundial de carne de frango dobrou em apenas duas décadas [cited 2016 Maio 8]. Rio de Janeiro; 2015. Available from: http://sna. agr.br/fao-producao-mundial-de-carne-de-frango-dobrou-em-apenasduas-decadas/

Sotherland PR, Spotila JR, Paganelli CV. Avian eggs: barriers to the exchange of heat and mass. Journal of Experimental Zoology1987;(Suppl. 1):8186 ,

Taylor G. Understanding high yield broiler incubation. Zootecnica International 1999;22(7):32-36.

Taylor LW, Sjodin RA, Gunns CA. The gaseous environment of the chick embryo in relation to its development and hatchability. 1. Effect of carbon dioxide and oxygen levels during the first four days of incubation upon hatchability. Poultry Science 1956;35:1206-1215

Taylor LW, Kreutziger GO. The gaseous environment of the chick embryo in relation to its development and hatchability. 2. Effect of carbon dioxide and oxygen levels during the period of the fifth through the eight days of incubation. Poultry Science 1965;44:98-106.

Taylor LW, Kreutziger GO. The gaseous environment of the chick embryo in relation to its development and hatchability;3. Effect of carbon dioxide and oxygen levels during the period of the ninth through the twelfth days of incubation. Poultry Science 1966;45:867-884.

Tazawa $\mathrm{H}$, Mikami T, Yoshimoto $\mathrm{C}$. Effect of reducing the shell area on the respiratory properties of chicken embryonic blood. Respiration Physiology 1971;13:352-360.

Tazawa $\mathrm{H}$. Adverse effect of failure to turn the avian egg on the embryo oxygen Exchange Respiration Physiology 1980;41:137-142. 
Boleli IC, Morita VS,

Matos Jr JB, Thimotheo M

Almeida VR

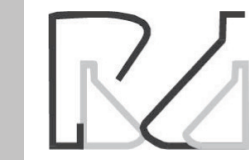

Tazawa H, Akiyama R, Moriya K. Development of cardiac rhythms in birds. Comparative Biochemistry and Physiology. Part A, Molecular \& Integrative Physiology 2002;132(4):675-689.

Tazawa H, Andrewartha SJ, Burggren WW. Development of hematological respiratory variables in late chicken embryos; the relative importance of incubation time and embryo mass. Comparative Biochemistry and Physiology A; Comparative Physiology 2011;159:225-233.

Tazawa H, Andrewartha SJ, Burggren WW. Acute regulation of hematocrit and blood acid-base balance during severe hypoxic challenges in late chicken embryos (Gallus gallus). Respiration Physiology and Neurobiology 2012;184(1):86-96.

Tona K, Bamelis F, Ketelaere B, Bruggeman V, Moraes VMB, Buyse J, et al. Effects of egg storage time on spread of hatch, chick quality and chick juvenile growth. Poultry Science 2003;82:736-741.

Tona K, Onagbesan O, Bruggeman V, Mertens K, Decuypere E. Effects of turning duration during incubation on embryo growth utilization of albúmen, and stress regulation. Poultry Science 2005;84:315-320.

Tona JK, Onagbesan O, Bruggeman V, De Smit L, Figueiredo D, Decuypere E. Non-ventilation during early incubation in combination with Dexamethasone administration during late incubation;1. Effects on physiological hormone levels, incubation duration and hatching events. Domestic Animal Endocrinology 2007;33:32-46.

Tullett SG, Burton FG. Factors affecting the weight and water status of the chick at hatch. British Poultry Science 1982;23:361-369.

Turner JS. On the thermal capacity of a bird's egg warmed by a brood patch. Physiological Zoology 1997;70:470-480.

Tzschentke B and Nichelmann M. Influence of prenatal and postnatal acclimation on nervous and peripheral thermoregulation. Annals New York Academy Sciences 1997;813(15):87-94.

Van der Pol CW, van Roovert-Reijrink IAM, Maatjens CM, van den Brand $\mathrm{H}$, Molenaar R. Effect of relative humidity during incubation at a set eggshell temperature and brooding temperature posthatch on embryonic mortality and chick quality. Poultry Science 2013;92(8):21452155

Van der Pol CW, van Roovert-Reijrink IA, Maatjens CM, van den Anker I, Kemp B, van den Brand $\mathrm{H}$. Effect of eggshell temperature throughout incubation on broiler hatchling leg bone development. Poultry Science 2014:93:2878-2883.
Poultry Egg Incubation: Integrating and Optimizing

Production Efficiency

Van der Sluis W. Egyptians hatch eggs the traditional way. 2011 [cited 2016 Mar 17]. Available from: http://www.worldpoultry.net/Breeders/ Incubation/2011/4/Egyptians-hatch-eggs-the-traditional-wayWP008725W/.

Visschedijk AHJ, Ar A, Rahn H, Piiper J. The independent effects of atmospheric pressure and oxygen partial pressure on gas exchange of the chicken embryo. Respiratory Physiology 1980;39:3-34.

Verhoelst E, De Ketelaere B, Decuypere E, De Baerdemaeker J. The effect of early prenatal hypercapnia on the vascular network in the chorioallantoic membrane of the chicken embryo. Biotechnology Progress 2011;27(2):562-570

Walstra I, Ten Napel J, Kemp B, van den Brand H. Temperature manipulation during layer chick embryogenesis. Poultry Science 2010;89:1502-1508.

Wilson HR,Douglas CR, Kalch LH. Bobwhite quail production. Poultry Science 1975;75-81.

Wilson HR. Physiological requirements of the developing embryo;temperature and turning. In: Tullet SG, editor. Avian incubation. London: Butterworhts; 1990. p.145-156.

Wilson HR. Interrelationships of egg size, chick size, post-hatching growth, and hatchability. World's Poultry Science Journal 1991;47:5-20.

Wilson HR. Physiological Requirements of the Developing Embryo;Temperature and Turning. In;Avian Incubation. Poultry Science Symposium 1991;22:145-156.

Wineland MJ, Mann KM, Fairchild BD, Christensen VL. Effect of high and low incubator temperatures at different stages of development upon the broiler embryo [abstract 180]. International Poultry Scientific Forum; 2000a; Atlanta, Georgia. Estados Unidos; 2000.

Yahav S. Alleviating heat stress in domestic fowl- Different strategies. Journal of World Poultry Science 2009;65:719-732.

Zhang $H$, Burggren WW. Hypoxic level and duration differentially affect embryonic organ system development of the chicken (Gallus gallus). Poultry Science 2012;91:3191-3201. 